\title{
Representaciones mentales de los docentes frente a la modernidad y la tecnología ${ }^{1}$
}

\author{
Edien Julián Charria Suárez ${ }^{2}$, Norma Graciela Castaño Castro ${ }^{3}$, \\ Francisco Javier lavao González ${ }^{4}$, Adriana Patricia Álvarez Sepúlveda ${ }^{5}$, \\ Zulma Carolina Castro Pérez ${ }^{6}$
}

\begin{abstract}
Resumen
Pensar en transformaciones educativas, permite indagar todos los elementos que intervienen en el proceso educativo. Esta investigación de corte cualitativo con enfoque socio - histórico, se desarrolló buscando comprender las representaciones mentales frente a la modernidad y la tecnología, para educar desde la diversidad de los docentes de básica primaria de cuatro instituciones educativas de Colombia. Los hallazgos se obtuvieron a partir de los análisis e interpretaciones de la teoría y los instrumentos fueron insumo para comprender la representaciones mentales como proceso complejo que se desarrolla por medio de modelos mentales y que se evidencia en la forma como el maestro explica y representa los objetos y fenómenos sociales importantes en la educación. Logrando determinar la representaciones mentales, proposicionales, analógicas, estructurales e imágenes contextuales e indicando estrategias que apoyan el proceso de enseñanza -aprendizaje, luego de una reflexión crítica de la interpretación mental del docente, se exhorta a reflexionar en su quehacer pedagógico.

Palabras claves: Representaciones mentales, modelo mental, modernidad, pedagogía, proceso, tecnología, docente, educación.
\end{abstract}

1 Recibido: 17 de febrero de 2016. Aceptado: 01 de mayo de 2016.

2 Magister en educación desde la diversidad; Licenciado en Educación Básica con énfasis en matemáticas, Universidad Santo Tomás de Bogotá. Labora en Institución Educativa Otoniel Rojas Correa, del departamento del Huila, Colombia. Correo electrónico: ejulicha@hotmail.es

3 Magister en educación desde la diversidad; Licenciada en Pedagogía Infantil, de la Universidad Sur colombiana, Neiva. Labora en la Fundación Social Amor y Vida, regional Neiva, Huila. Correo electrónico: normita1014@hotmail.com

4 Magister en educación desde la diversidad; Licenciado en Educación Básica con Énfasis Educación Física, Recreación y deporte de la Universidad Sur colombiana, Neiva. Labora en la Institución Educativa Santa Rosalía, en el Huila, Colombia. Correo electrónico: frajalago.5@hotmail.com

5 Magister en educación desde la diversidad; licenciada en Educación Básica con énfasis en ciencias Naturales y educación ambiental, Universidad Católica del Oriente de Rio Negro Antioquia. Labora en la Institución Rural Simón Bolívar, en el departamento de Caquetá, Colombia. Correo electrónico: adrianapas@hotmail.es

6 Magister en educación desde la diversidad; Psicóloga de la Universidad Cooperativa de Colombia; especialista en Psicología de la Salud, Universidad Sur colombiana. Docente universitaria Universidad Minuto de Dios, Huila y directora del presente trabajo. Correo electrónico: zulmacastro77@gmail.com 


\section{Abstract \\ Mental representations of teachers to modernity and technology}

To think about educational transformations, allow us to investigate all the elements that have relation with the educational process. This research is qualitative, focus on the social-historical approach, it was developed in order to understand the mental representations in modernity and technology, in order to educate from the diversity with teachers of primary school of four educational institutions of Colombia. The results were obtained from the analyses and interpretations of the theory and the instruments as input to understand mental representations, as a complex process that developed mental models and demonstrated the way the teacher explains and represent the objects and social phenomena in the education. Trying to determine mental representations, propositional, analogical, structural and contextual images that indicating strategies that support the teaching-learning process, after a critical reflection of mental interpretation of teachers, It exhorts to think in the pedagogic occupation.

Keywords: mental representations, mental model, modernity, pedagogy, process, technology, teacher, education.

\section{Presentando y justificando}

\section{La modernidad es el tiempo en el que el tiempo tiene historia.}

\section{Zigmund Bauman}

La modernidad es historia, es donde la humanidad se dio cuenta de sí misma y su lugar en el planeta, se supo historia y luego se comprendió como devenir, lo que se tradujo en exceso de progreso, de cuyos fracasos hoy sabemos. La experiencia del estudio investigativo sobre: las representaciones mentales de los docentes frente a la modernidad y la tecnología, corresponde a maestros de básica primaria de las instituciones Otoniel Rojas Correa, Santa Juana de Arco, Promoción Social, Santa Rosalía, del Huila, y Simón Bolívar de El Doncello - Caquetá, bajo la asesoría de la magíster Zulma Carolina Castro Pérez, durante el periodo 2014-2015.

La educación del siglo XXI implica grandes retos, que van de la mano con las transformaciones sociales y culturales provocando un cambio de pensamiento en el devenir del maestro y las generaciones que se propone formar, en la actualidad se habla a voces de diversidad, modernidad y tecnología, pero su significado pareciera perderse en un mar de sensaciones, no es fácil hablar de transformación de representaciones mentales de los docentes, con respecto a la utilización de la tecnología, como herramientas que permiten la motivación para dinamizar las prácticas de aula, sin tener una verdadera sensación de claridad de estas palabras pronunciadas a diario y a la vez tan desgastadas en los discursos de educación.

"En nuestros días la modernidad luce agotada y sus triunfos son más bien reducidos" (Gonzalez, 2011, p. 14) en efecto, la modernidad encierra un caótico paisaje que sugiere una reflexión sustancial desde el terreno educativo, escuchando el sonido de los silencios de los docentes, a través de su postura respecto a la modernidad concepto tan usado a diario, que pareciera que todo está dicho, desde la perspectiva de Bauman,(2010, p.15) en la modernidad 
líquida, fundamenta una connotación real a un proceso de cambio donde el tiempo y lo diferente está ligado a los fenómenos sociales, pero sus significado y la manera de hacer lectura a la modernidad depende no solamente en decodificar el concepto científico sino el significado para el tiempo y por ende para el maestro y la levedad de su ser.

Por otro lado la tecnología, como motor humano, es el producto del proceso de la ciencia y el conocimiento para generar el avance; por ende encierra un recurso que por sí sola no genera transformación social, es decir, la interacción sujeto, modernidad, y tecnología, promueve el proceso que permite su re-significación.

Un proyecto investigativo como este, genera reflexión e interés en la medida en que se realiza una lectura de la realidad a través de las representaciones mentales de los docentes frente a dos palabras generadoras de gran interés en el mundo globalizado; si bien es cierto, que el docente es visto como sujeto de transformaciones sociales, es indispensable llegar a generar procesos innovadores en el campo educativo desde la mirada del maestro, a través de su accionar social.

Desde el punto de vista pedagógico, didáctico, se justifica el desarrollo del presente estudio, que permitirá explorar nuevas realidades, generando conciencia reflexiva, pretendiendo el mejoramiento de la calidad de la educación a través de las representaciones mentales de los docentes como agentes de cambio social.

\section{Aprender de lo estudiado}

Para abordar las representaciones sociales de los docentes se tuvieron en cuenta las siguientes investigaciones. En el plano internacional: La teoría de los modelos mentales de Johnson-Laird y sus principios: una aplicación con modelos mentales de célula en estudiantes de curso de orientación universitaria, de Rodríguez, Marrero, Moreira (2001) efectuada en la zona norte de la Tenerife, islas Canarias, España, de corte social y metodología estudio de caso tuvo como objetivo abordar en primer lugar la propia teoría, lo que da cuenta de sus rasgos más característicos. Sintetizando su aplicación en la realidad social, son precisamente, prácticos, en la acción permiten delimitar criterios que facilitan la interpretación de lo que son modelos mentales como mecanismos de representación humana, que pone en juego, como intermediarios en el procesamiento de la información. Una información que es percibida o concebida de diferentes maneras, en función de modelos mentales, en la perspectiva de Johnson-Laird un constructo plausible, un modelo mental aplicable como intermediario para interpretar las representaciones que el mundo construye para representar la información que escribe.

La investigación "Innovación Educativa y Comunicación", realizada por Partida (2013), desarrollada en España, de enfoque social, tuvo como objetivo demostrar como la acción pedagógica se sirve de la acción comunicativa para producir, distribuir, consumir e intercambiar información significativa y concluye; afirmando cómo la enseñanza y el aprendizaje como sistema de producción social de comunicación, permite entender la naturaleza, las características y los efectos de la comunicación en la acción pedagógica; y la acción comunicativa se refiere al funcionamiento de un sistema comunicativo que implica trabajo expresivo llegando a entender cómo el aprendizaje es un sistema de producción social, útil para las re significaciones.

Seguidamente Lucena, Martin, y Días (2005), "las actitudes que los docentes y futuros docentes poseen respecto a la formación en tecnología de la información y la comunicación (TIC) aplicadas a la educación"; investigación efectuada en la provincia de Granada en España de corte social, planteó como objetivo principal indagar las actitudes que los 
docentes y futuros docentes poseen respecto a la formación en tecnología de la información y la comunicación aplicada a la educación.

Concluye que los futuros docentes creen que las TIC aplicadas a la educación pueden ser utilizadas para el desarrollo de las actividades de cada una de las áreas, es muy importante destacar la afirmación que hacen, que en unas áreas se utilizan más que en otras. De igual manera, afirman que las TIC son utilizadas como medios didácticos y aseveran que la mayoría de los docentes y futuros docentes perciben que necesitan formarse en TIC aplicadas a la educación o actualizar su formación.

En el contexto nacional, la investigación "Tecnologías de la Información y la Comunicación para la Mediación Pedagógica”, desarrollada por García (2015), de corte social, tiene como objetivo articular la pedagogía y la tecnología, direccionar las posibilidades de los recursos tecnológicos hacia la generación de experiencias y actividades en escenarios de aprendizaje para favorecer la interacción estudiante-docente, estudiante-estudiante y estudiante-contenido. Reconociendo la contribución pedagógica y comunicativa que tiene los recursos tecnológicos, como mediadores y facilitadores del proceso de aprendizaje.

Igualmente, Arcos, Paz, Salazar, Ríos (2012), pertenecientes al macro proyecto de investigación desarrollado por la universidad de Manizales, titulada "El miedo en las prácticas pedagógicas" (Ríos, 2012), utilizaron la metodología: histórico-hermenéutico como horizonte investigativo, el objetivo a investigar fue un grupo de docentes latinoamericanos reconocidos por su significativo aporte en el desarrollo de la educación desde el punto de vista de las responsabilidades sociales sin temor, asumiendo el reto de vencer los miedos de la interpretación errónea. A modo de síntesis el miedo de los docentes está en mostrar su lado humano, el lado del error, del desconocimiento y de la mala interpretación; que el profesor es un baúl de conocimientos a impartir a unos estudiantes pasivos pero que además no debe mostrar su desconocimiento ni la creación de aprendizaje junto a sus estudiantes.

Del mismo modo, Parra (2012), en la investigación "TIC, Conocimiento, educación y competencias tecnológicas en la formación de maestros, desarrollada con una metodología de corte social, con el objetivo de cartografiar las relaciones entre agentes, saberes e instituciones en el campo de la producción discursiva sobre las TIC y la educación en Colombia entre finales de la década de los setenta y los primeros años del siglo XXI. Concluyendo, que hablar de cambios en el sentido del conocimiento no significa demostrar que la razón instrumental ha desaparecido o que ha sido reemplazada, se trata de documentar cómo se actúa, refina y complejiza mediante nuevas maneras, estrategias y agentes.

También, Barrios (2011), "La relación Docente - Estudiante en el siglo XXI: Uso y consumo de los nuevos medios en la sociedad de la información y la comunicación en el proceso de aprendizaje" realizada en Colombia, de corte social; cuyo objetivo fue entender como la sociedad de la información y de la comunicación ha traído consigo múltiples cambios en cada uno de los procesos que ejerce el ser humano para su desarrollo social. La información ha tomado gran importancia y se convirtió en fuente de productividad y poder, pues al lado del conocimiento está presente en cualquier lugar permitiendo la flexibilidad de ejercer labores desde diversos sitios y de esta manera permear las formas de producción - consumo y las relaciones sociales entre los seres humanos. Por lo anterior, se puede dar cuenta que en la sociedad actual los medios de comunicación afectan las representaciones mentales, el proceso educativo y al mismo tiempo contribuyen a las re significaciones sociales y culturales. 


\section{Problemas y objetivos}

Muchos son los problemas que nos interesan, no obstante nos hemos decidido por la siguiente pregunta: ¿Cuáles son las representaciones mentales de los maestros de las Instituciones Educativas Otoniel Rojas Correa, Santa Juana de Arco, Promoción Social, Santa Rosalía, del Huila y Simón Bolívar de El Doncello, Caquetá, frente a la modernidad y la tecnología?

A esto se nos suman las objetivaciones como puntos de acción. Nos interesa: Comprender las representaciones mentales frente a la modernidad y la tecnología de los docentes de básica primaria de cuatro instituciones educativas del departamento del Huila y una institución educativa del departamento Caquetá, para educar desde la diversidad.

En sus especifidades nos hemos centrado en:

- Reconocer las representaciones mentales de los maestros y sus implicaciones frente a sus prácticas pedagógicas.

- Identificar las diferentes estrategias y metodologías de los educadores en el desarrollo de sus prácticas pedagógicas en el uso de la tecnología.

- Analizar las representaciones mentales de los docentes frente a la modernidad y la tecnología para educar desde la diversidad.

\section{Por las teorías y su entramado}

Las representaciones mentales en el transcurso del tiempo han evolucionado, perfeccionándose para generar diferentes resultados en lo relacionado a la epistemología, La teoría de Piaget sostiene que ni el procesamiento de la información ni el desarrollo son de dominio específico sino general. El desarrollo implica la construcción de cambios que afectan la estructura de la representación, generales para todos los dominios y que afectan al sistema cognitivo por igual. Esta es una conse- cuencia de la postura epistemológica de Piaget: "cualquier cambio producido en el sistema cognitivo afectará a la estructura de conjunto como un todo, conducirá a una estructuración nueva, distinta del sujeto y del objeto". (Piaget, 1955). El conocimiento no es una copia del mundo, por el contrario al igual que en la tradición racionalista la información sobre los objetos, proporcionada por los sentidos es interpretada y está condicionada por los marcos conceptuales que intervienen en la asimilación. Es aquí, donde las representaciones mentales se fundamenta con la Teoría de los Modelos Mentales para el razonamiento de Johnson Laird (19831990), donde el proceso de inferencia no puede reducirse a la lógica ni al empleo de reglas formales que operan sobre las representaciones proposicionales. Según su Teoría, el razonamiento consistiría en la construcción y manipulación de modelos mentales de naturaleza analógica; expuesto claramente como:

Los proponentes de las representaciones proposicionales están limitados a suponer que el razonamiento consiste en la manipulación de tales representaciones usando reglas formales de inferencia. Una vez que admitimos la existencia de imágenes o modelos como representaciones, la otra posibilidad es evidente. El razonamiento podría consistir en la construcción de tales representaciones, la formulación de una conclusión basada en ellas y la búsqueda de otras tales representaciones sobre las premisas para testear la validez de la conclusión. Esta idea está en el corazón de la teoría de los modelos mentales para el razonamiento. (Johnson Laird, 1996, p.99).

De esta manera, las representaciones mentales; son formas simbólicas de reproducir la realidad en ausencia de ésta. Para dar sentido a aquello que nos rodea; las representaciones se organizan en estructuras y se construyen partiendo 
de un contexto social propio de un grupo determinado. De esta forma, se hace imprescindible que el maestro comprenda la modernidad como la define Bauman (2000, p. 16):

\section{La modernidad puede significar} muchas cosas e interpretarse de diferentes maneras, sin embargo, está presente en la realidad de la vida actual como un rasgo articulare interesante que hace la diferencia al cambio y al contexto y dimensiones espacio - tiempo.

De lo anteriormente expuesto, la modernidad conlleva a un proceso de cambio en donde el tiempo, lo diferente están muy ligados como fenómenos puramente humanos, y el estudio se enfoca en las representaciones mentales, lo que indudablemente hace que la modernidad conlleve a la ciencia a una serie de cambios que resultan evidentes en la tecnología. Hacer de la tecnología un facilitador para un proceso cambio social permite entender lo que Según (Castells, 2011, p. 34) en su libro; La era de la información: economía, sociedad y cultura, expone:

Para reconocer los pasos preliminares en esa dirección, debemos tomar en serio la tecnología, utilizándola como punto de partida de esta indagación; hemos de situar este proceso de cambio tecnológico revolucionario en el contexto social donde tiene lugar y cobra forma; debemos tener presente que la búsqueda de identidad es un cambio tan poderoso como la transformación tecno-económica en el curso de la nueva historia.

En este caso, es importante señalar que el estudio de estrategias frente a las representaciones mentales, los docentes asumen una posición variable a los cambios que ocurren o se generan y que exigen preparación porque, la evolución del proceso educativo debe asumirse con responsabilidad para entender y enfrentar las nuevas formas de educar.

\section{Por los métodos}

La investigación de carácter cualitativo, de corte socio - histórico; permite el cuestionamiento constante de las representaciones mentales actuales sobre la modernidad de los docentes con respecto a la utilización de la tecnología, como herramientas que permite la motivación para dinamizar las prácticas de aula.

La metodología social lleva a la investigación científica de corte socio - histórica hacia el desarrollo humano, porque se basa en el estudio del contexto, hacer miradas críticas sobre el objeto de estudio; respetando la diversidad de los individuos y de las culturas, como lo menciona Briones (2009, p. 151) en cuanto a la teoría socio histórico cultural de Vygotsky:

La actividad mental (percepciones, memoria, pensamiento, etc.) es la característica fundamental que distingue exclusivamente al hombre del ser humano. Esa actividad es resultado de un aprendizaje sociocultural que implica la internalización de elementos culturales que tienen un significado socialmente.

La presente investigación inicia con las afectaciones que como docentes se vivenciaron en el contexto, lo que permitió identificar los interrogantes, la temática, los objetivos que empezaron a estructurar el proyecto investigativo. Posteriormente se seleccionaron los antecedentes y las teorías que orientaron y soportaron cada uno de los hallazgos que resultaron teniendo en cuenta el enfoque metodológico, los instrumentos, las técnicas de recolección de la información, la teoría y los análisis del grupo investigador.

Se pretendió encontrar la ruta más adecuada para cumplir con los objetivos, permitiendo realizar miradas críticas a la realidad, como también dar inicio a nuevas problemáticas relacionadas con la investigación.

Las técnicas para la recolección de la información se seleccionaron luego de una 
evaluación minuciosa, logrando identificar los instrumentos apropiados para una investigación de este corte en educación; siendo la entrevista semiestructurada un instrumento que permite mayor libertad de indagación, porque "es aquella en que existe un margen más o menos grande de libertan para formular preguntas y respuestas" (Sabino, 1992, p. 18) y la carta asociativa como técnica complementaria fueron claves en la recolección de la información sin dejar de lado la pesquisa de documentos, la biografía, la autobiografía y la observación participante, todo lo anterior permitió la triangulación de la información para una mejor comprensión y reflexión.

La población elegida para la investigación correspondió a trece docentes de básica primaria de las instituciones educativas Otoniel Rojas Correa, Santa Juana de Arco, Promoción Social, Santa Rosalía, del Huila, y Simón Bolívar de El Doncello, Caquetá; oriundos del departamento del Huila y Caquetá, licenciados en educación, que han ejercido su profesión en las instituciones educativas mencionadas, vinculados a este proceso con una trayectoria académica continua en estas instituciones educativas.

\section{Hallazgos}

Una vez aplicadas y analizadas las entrevistas semiestructurada, autobiografía, cartas asociativas se obtuvieron los siguientes hallazgos. Para la investigación resultó importante definir unas palabras fuerza, lo que también se conoce como categorías.

- Categoría de representaciones mentales: Como recopilación del estudio se define representaciones mentales como aquella forma material o simbólica de dar cuenta de algo real en su ausencia, están organizadas en estructuras que permiten darle sentido al entorno y de esta manera se dinamiza el proceso del campo educativo.
- Categoría maestro: Maestro, es el profesional de la educación que se ha preparado específicamente para desarrollar el proceso educativo, obteniendo conocimientos en pedagogía, didáctica, continua capacitación, conocimiento al ser, al saber y aprovechando los recursos, la tecnología y los medios que le permitan enseñar a los estudiantes con objetividad, veracidad y racionalidad.

- Categoría modernidad: La modernidad como categoría sociológica, es una figura del cambio y de la transitoriedad, de la desregulación y la libertad de mercados. Igualmente la modernidad autentica se enfoca en lo diferente, la autonomía, la libertad, la autoafirmación de ser contrario a la visión errónea de estandarizar, unificar, homogenizar y la educación como proceso, se enfoca en liberar y facilitar la libertad.

- Categoría tecnología: La tecnología, como motor humano, es el producto del proceso de la ciencia y el conocimiento para generar el avance, el cambio, las transformaciones de procesos sociales, de esta forma, la tecnología es un recurso de los seres humanos que por sí sola no genera transformación social, es decir, la interacción sujeto, modernidad, tecnología, se da el proceso que permite su significación.

\section{Representaciones mentales de los docentes: una mirada reflexiva desde la óptica del maestro}

El cómo hacemos las representaciones y la forma en que ello acaece es un fenómeno de bastante interés; en esta instancia, se hallaron las representaciones mentales de los maestros que se estructuran en tres modelos distintos: proposicionales: las que mantienen un orden lógico. Análogos estructurales; que mantienen 
semejanza entre dos elementos diferentes. Imágenes; es una representación visual, que manifiesta la apariencia visual de un objeto real o imaginario.

Sin embargo es importante aclarar que existen otros modelos mentales como: los intuitivos y por su característica es complejo de formalizar, pero también pueden generar otras categorías de análisis, porque las representaciones mentales son dinámicas y un modelo mental nunca es completo; es aquí en la reflexión y el análisis precisamente donde el maestro puede potenciar sus habilidades siendo recursivo utilizando la modernidad y la tecnológica para enriquecer el proceso de enseñanza - aprendizaje de acuerdo a lo que afirma el docente consultado en la tercera entrevista: "trato de ser persistente, no me rindo en el primer obstáculo, trato de mirar diferentes estrategias para llegar a mis estudiantes", reafirmando lo dicho por Jhonsson Laird (1998, p. 111)

Los Modelos Mentales, son modelos de trabajo, de situaciones de acontecimientos del mundo y que mediante su manipulación, nos permite comprender y explicar fenómenos de ese mundo y actuar de acuerdo de las predicciones resultantes.

Las diferentes representaciones mentales de la modernidad y la tecnológica se hallan de conceptualizaciones y de las categorías que se tuvieron en cuenta en los instrumentos aplicados a los maestros como sujetos de investigación permitiendo afirmar que las representaciones mentales son herramientas de trascendental importancia para el docente en su labor.

Los hallazgos de la investigación permitieron observar que el $80 \%$ de docentes aplican las representaciones mentales de la modernidad y la tecnología por medio de modelos proposicionales, porque lo hacen mediante cadenas de símbolos, innatos a su cultura, contexto social, de manera sencilla, permitiendo formulaciones y enunciados; es decir, un trabajo que implica una construcción racional. Se deduce de las entrevistas aplicadas, que revelan valores significantes y que tienen como intermediario el lenguaje propio del contexto, que actúa como lo dice Ibáñez (1986 p. 41), en nuestra sociedad "el lenguaje funciona como equivalente general de valor, de todas las practicas significantes". Lo que equivale a no dejar las representaciones como simples aplicaciones de fórmulas lógicas que nos permitan hacer inferencias propias del mundo real, evidenciado en uno de los instrumentos de la investigación, entrevistado no.1, cuando se refería a la práctica en el aula "...yo las doy por medio de cuentos, yo siempre he enseñado a base de cuento... yo le manejo mucho el tablero en los mapas porque yo me defiendo más".

El $15 \%$ de docentes se mantienen en una representaciones mentales estática en cuanto a la modernidad y la tecnología como se puede leer en la encuesta No. 1: "No he usado el computador y el vídeo beam; el celular sí, sí lo utilizan para las cosas de la clase, pues sí, pero para otras cosas no. Porque es un distractor para que ellos aprendan". Se mantienen de un modelo análogo estructural, donde se centran en su parte constitutiva externa, no trascienden del corte pedagógico tradicional, conservan estáticamente las ideas de la modernidad tecnológica, no evolución al ritmo del avance social y tecnológico del mundo. Aquí, es trascendental lo que Bauman (2015, p. 21) en su texto la modernidad liquida para la educación, afirma:

Liberarse significa literalmente deshacerse de las ataduras que impiden o constriñen el movimiento, comenzar a sentirse libres de actuar y de moverse [...] actuar según el propio deseo, implica alcanzar el propio equilibrio entre los deseos, la imaginación y la capacidad de actuar: nos sentimos libres siempre y cuando nuestra imaginación no exceda nuestros verdaderos deseos y ni una ni los otros sobre pasen nuestra capacidad de actuar. 
Del mismo modo, se halló que el $5 \%$ de los maestros constantemente resignifican su pensar de la modernidad y la tecnología como personas sociales encargadas de orientar, reorganizar y reconstruir la cultura, lo afirmó el docente en la encuesta no. 4 diciendo:

...A medida que va dando los años, a medida que va pasando el tiempo uno se va dando cuenta qué cosas debe fortalecer y qué cosas debe mejorar y qué cosas están más o menos bien. Entonces, eso se hace de manera progresiva y permanente y constante.

Este proceso de razonamiento estructura un modelo mental que se enfoca en imágenes y permite mayor información, video expansión porque es la representación interna con mayor grado de aproximación lógica de los objetos y fenómenos sociales. Como lo aclara (Jhonsson Laird, 1996, p.99)

El razonamiento podría consistir en la construcción de tales representaciones, la formulación de una conclusión basada en ellas y la búsqueda de otras tales representaciones sobre las premisas para testear la validez de la conclusión. Esta idea está en el corazón de la teoría de los modelos mentales para el razonamiento.

La teoría de Jhonsson Laird, admite comprender la forma de representación mental de modernidad y la tecnología. Se reconstruye mediante procesos dinámicos complejos, permitiéndole establecer inferencias y deducciones propias del lenguaje de programación, de la modernidad y la tecnológica, necesaria para comprender los procesos cognitivos a desarrollar en las aulas de clase cuando se enseña desde la diversidad.

Ahora bien, expuestos los hallazgos relativos a las representaciones mentales de los docentes, es importante hacer una lectura reflexiva hacia la modernidad, puesto que, su forma de comprenderla como una figura de cambio social, permite reestructurar la representación mental, evidenciándose en las estrategias pedagógicas porque, según la relevancia que le demos a los atributos característicos y su capacidad de reflejar permitió estructurar y relacionar las estrategias pedagógicas como:

- Estrategia tradicional

- Estrategia metodológica dual

- Estrategia metodológica moderna

Así mismo, en lo referente a estrategias metodológicas, se presentan la posición tradicional referenciando la entrevista 1, la maestra expresa: "yo, toda mi vida como maestra he dado mis clases así, y me ha funcionado", no darle relevancia a la modernidad hace que las estrategias metodológicas no se re signifique y obstaculizan lo afirmado por García (2015, p. 130) En la investigación Tecnología de la información y la comunicación para la mediación pedagógica:

Hablar de cambios en el sentido del conocimiento no significa demostrar que la razón instrumental ha desaparecido o que ha sido reemplazada, se trata de documentar cómo se actúa, refina y complejiza mediante nuevas maneras, estrategias y agentes.

Otros docentes se inclinan por una posición dual, es decir, reconocen las herramientas tecnológicas y su importancia en la práctica pedagógica pero no las utilizan por considerar mayor responsabilidad, más trabajo, y menos tiempo en la interacción con los estudiantes: "no he usado el computador ni el vídeo beam, el celular sí, sí lo utilizan para las cosas de la clase" afirmado en la encuesta n. 1; es importante tener en cuenta lo afirmado por Bijker et al. 1987, citado por Castell (2011, p. 35) "puesto que la tecnología está en la sociedad y si se colocan barreras no puede ser comprendida o representada sin sus herramientas técnicas". Será muy difícil el cambio y la posición positiva a su interacción. 
Sin embargo, un grupo reducido se enfoca en la tecnología moderna afirmado por el entrevistado tres, "buscar nuevas metodologías, para que los niños adquieran nuevas conductas y no se sientan regañados, oprimidos o como en el lugar inapropiado sino que se sientan a gusto", como lo afirma Ibáñez (1986, p. 41) "Indiscutiblemente, el lenguaje de la modernidad y la tecnológica es esencial para los cambios positivos y metodológicos de la educación actual".

Después de analizar y categorizar las estrategias metodológicas de los maestros, es importante iniciar con los hallazgos concerniente al comportamiento, se presentan tres estilos: pasivo, mediático y moderno. Los pasivos no le asignan ninguna relevancia al significado de cambio, a lo diferente, porque permanecen en un nivel estándar frente a la modernidad y la tecnológica, expresa un nivel de adaptación y conformidad constante, permanente y lo ratifican cuando dicen: "que no utilizo mucho la tecnología en sus labores de clase, es decir, no mucho de ciudadano virtual", afirmado en la entrevista 5, en cuanto a los miedos de los docentes también contamos con investigaciones que afirman:

La tarea como educadores está permeabilizada de una carga emocional que en muchas ocasiones es representada por el miedo, el miedo como herramienta y el miedo como necesidad para el desarrollo de nuestro rol como educadores pensando en las responsabilidades sociales y las tareas como orden, disciplina, compromiso curricular para cumplir.(Garzón Arcos, Botina Paz, Salazar Benavides, \& Rios Patiño, 2013).

Indudablemente, el miedo es un factor que mantiene a muchos docentes en este círculo pasivo.

De igual manera, existe otro nivel de docentes que se enfoca como mediáticos, es decir, momentáneamente se interesan por la modernidad tecnológica pero prontamente pierden el interés. Estos docentes mantienen una motivación hacia la modernidad y la tecnología, afirman reiterativamente en varias entrevistas; "sí, soy un fanático de la tecnología,". Un sujeto que con impulsos mediáticos muestra una pasión exagerada que fácilmente se puede considerar como un fanático, que realmente no trasciende.

Un tercer grupo se enfoca en un comportamiento moderno, es decir, actualizado equilibradamente dentro de la institución educativa y al respecto se puede leer en la entrevista 6: "utilizamos todo lo que sea moderno y tecnológico, pero priorizando mi actitud como docente". Otra característica hace referencia a la capacidad de penetración de los efectos de las nuevas tecnologías (Castell, 2011, Pág. 104), es decir, un maestro con conocimientos y habilidades para diseñar estrategia metodológicas acordes a los diferentes ritmos de aprendizajes de cada uno de los niños y las niñas, a través del uso de las herramientas producto de ciencia que permitan dinamizar la educación como un proceso en el cual se reconstruye la sociedad y su cultura a partir de la diferencia, característica de una educación desde la diversidad.

La investigación, permitió determinar que las representaciones mentales de los maestros frente a la modernidad y la tecnología se estructuran mediante tres modelos mentales, es decir proposicionales, análogos - estructurales e imágenes, igualmente de comprendió la trascendencia de la modernidad y la tecnológica desde el punto de vista educativo como figura de cambio y motor humano que de una $u$ otra manera incide a fundamentar las estrategias metodológica y los comportamientos para que los docentes brinden múltiples oportunidades a los estudiantes y generar espacios para trascender en la aplicabilidad de procesos nuevos superando las proyecciones tradicionales, duales y centrándose en la estrategia metodológica moderna para reconstruir el saber con la dinámica de la evolución permanente de 
la educación en el contexto contemporáneo. Del mismo modo, resulta interesante señalar que surgen de estos hallazgos la categoría emergente:

Modernidad tecnológica: la modernidad tecnológica concebida desde diferentes paramentos en el contexto contemporáneo, registra múltiples conceptos, se considera como una figura de cambio, o a lo diferente que permite los avances de la ciencia y la tecnología para brindar un mejor nivel de vida, igualmente como los procesos de estandarización y homogenización en el avance científico sin mayor autonomía en la dimensión humana. Para otros equivale a las teorías nuevas e innovadoras que se proyectan a la autonomía la libertad, funcionalidad de los seres humanos con sus derechos y proyecciones, en el campo educativo se enfoca desde el punto de vista de la investigación como una proyección humana y autentica que recurre a los beneficios que ofrece los avances tecnológicos en bien del proceso de enseñanza - aprendizaje y que el maestro potencializa a través de las representaciones mentales.

\section{Conclusiones}

Al hablar de conclusiones, al querer resumir los grandes encuentros de una investigación siempre nos emergen sorpresas. El estudio de las representaciones mentales de los docentes frente a la modernidad y la tecnología, permitió considerar la comprensión del proceso, construcción de conocimiento, acceso a la ciencia y a la epistemología enfocada en la utilización de la modernidad tecnológica para educar desde la diversidad, en donde no existe un único modelo mental sino múltiples viables de aprovechar por el docente en el proceso educativo.

La investigación permitió identificar diversas estrategias y metodologías aplicadas por los maestros, porque resultan del proceso psicológico, como lo muestran los docentes, que son sujetos que están inmersos en un mismo contexto y para un mismo fin, pero sus representaciones mentales son diferentes, ellas se basan en las respuesta, actuaciones, significación y sus concepciones, elementos necesarios para construir el proceso de aprendizaje. Desde esta perspectivas la figura de cambio permite la reconstrucción de las representaciones mentales de los docentes, frente a la modernidad tecnológica, las realidades sociales y culturales, en aquellos docentes pasivos, conformistas o mediáticos, que de cierta manera, podría afirmarse, están negando al acceso y al espacio de los beneficios a la modernidad tecnológica.

La modernidad tecnológica es una herramienta construida por la ciencia para la reconstrucción de la sociedad y facilitar los procesos como el de aprendizaje desarrollado por los docentes - estudiantes, para asumir los retos que a futuro depara los avances científicos y tecnológicos para los cuales, es necesario superar barreras tradicionales, de miedos e ignorancias para competir con éxito en los retos diarios que el maestro afronta más cuando debe reconocerse el proceso de diversidad para identificar la dirección y desde allí construir sociedad más humana, digna, global, con aportes desde lo individual a lo colectivo.

Para tal efecto se puede mencionar a maestros preocupados por brindar una educación de calidad, aprovechando los recursos que el sistema brinda y sin ahorrar esfuerzos por dar lo mejor de sí para lograr este objetivo. La investigación representaciones mentales de los docentes frente a la modernidad y la tecnología, comprobó la realidad actual acerca del uso de la modernidad tecnológica, su importancia, trascendencia y proyección en el contexto contemporáneo.

\section{Recomendaciones}

Se recomienda a los docentes investigar, reflexionar, indagar en su quehacer pedagógico, acerca de la modernidad tecnológica, facilitando la flexibilidad, coherencia, la contextualización del currículo 
desarrollándolo a partir de la diversidad y comprender las representaciones mentales frente a la modernidad y la tecnología y las actitudes como una consecuencia de ellas, porque las actitudes, pueden ser afectadas por factores externos a las representaciones y además los modelos mentales nunca completos, sino, que se amplían y mejoran en la medida en la que se incorpora información.

Es recomendable para el cuerpo docente, darle significado al uso de la ciencia como herramienta que enriquece las estrategias metodológicas, porque familiariza los aprendizajes en los niños ofreciéndole oportunidades de construir su conocimiento de manera colaborativa con el apoyo de la modernidad tecnológica.

Se recomienda a la continuidad educativa realizar investigaciones y estudios acerca de las representaciones mentales de los docentes frente a la modernidad tecnológica para educar desde la diversidad, profundizando sobre otros niveles y categorías que también pueden servir de modelo a nuevas investigaciones, como fuente de consulta para solución de problemáticas entorno a este tema de actualidad.

\section{Bibliografía}

Ariza Porlán, R; García Rivero, A; Del Pozo Martín, R. (1998) Conocimiento profesional y epistemología de los profesores, ii: estudios empíricos y conclusiones. Revista Enseñanza de las ciencias. En https://www. google.com/url?sa=t\&rct=j\&q=\&esrc=s\&sou $r c e=w e b \& c d=2 \& c a d=r j a \& u a c t=8 \& v e d=0 a h$ UKEwizIM6F07vMAhWEox4KHePdAEIQF ggmMAE\&url=http $\% 3 \mathrm{~A} \% 2 \mathrm{~F} \% 2 \mathrm{Fwww}$.raco. cat $\% 2$ Findex.php\%2FEnsenanza $\% 2$ Farticl e\%2Fview\%2F21534\&usg=AFQjCNHAL9C 7jA9Rj2pcbNrPEcQ-zZrJog\&bvm=bv.12107 0826,d.dmo d.dmo

Barrios R, A. (2011), La relación Docente Estudiante en el siglo XXI: Uso y consumo de los nuevos medios en la sociedad de la información y la comunicación en el proceso de aprendizaje, Bogotá.

Bauman, Z. (2010) Modernidad Líquida. Buenos Aires: Editorial Fondo de Cultura Económica, Argentina.

Bauman, Z. (2015) Los retos de la educación en la modernidad líquida. Barcelona: Editorial: Gelisa.

Bijker, W, E., Thomas P. (1987). The social construction of technological systems: New directions in the Sociology and History of Technology. Cambridge: Cambridge, Mass., The MIT Press.

Briones G. (2009). Teorías de las ciencias sociales y de la educación epistemología. México: Editorial Trillas.
Calderon, J. (2011). Metodos de investigacion cualitativa. Los Etnográficos, 1-33. Recuperado de http://issuu.com/ los.etnograficos/docs/revista_digital. Catells M. (1996) La era de la información, economía, sociedad y cultura. Ed. Cast: Alianza Editorial.

Corvalán Bustos, M. (2013) Revista, Plumilla Educativa, edición número 12, diciembre del 2013. Práctica Pedagógica e InvestigaciónAcción. Manizales: Universidad de Manizales. Págs. 41-60.

Dilthey, W. (1980). introducción a las ciencias del Espíritu. Madrid: Alianza.

epistemología de los profesores, ii: estudios empíricos y conclusiones.

Garcia Naranjo, M. L. (2012). Tecnologia de la información y la comunicación para la mediación pedagógica. Ventana Informática No. 27, 129-141. Manizales: Universidad de Manizales.

Gelman, R. (1990) First principles organize attention to and learning about relevant data: Number and animate-inanimate distiction examples. Cognitive Science, 14: 79-106.

González González, M. A. (2010), Umbrales de indolencia. Educación sombría y justicia indiferente. Manizales: Universidad de Manizales,.

González González, M. A. (2011). Resistir en la esperanza, Tertulias con el tiempo. Pereira: Universidad Tecnológica de Pereira. 
González González, M. A. (2015). Miedos y olvidos pedagógicos. Rosario: Homosapiens

González González, M. A. (2016). Aprender a vivir juntos. Lenguajes para pensar diversidades e inclusiones. Buenos Aires: Noveduc.

Habermas, J. (1982). Conocimieto e Interés. Madrid: Tauros.

Hinojo Lucena, F. J; Fernández Martin, F, D. (2002). Las actitudes de los docentes hacia la formación en tecnología de la información y comunicación (TIC) aplicadas a la educación. Revista Contextos Educativos Nro. 5, Pp. 253-270. Granada: Universidad de Granada

Johnson-Laird, P. (1996) Images, Models, and Propositional Representations, en: Models of Visuospatial Cognition, Manuel de Vega, Margaret Jean Intons Peterson, Philip Johnson-Laird, Michel Denis y Marc Marschark, Cap 3 pp 90-126. New York: New York, Oxford, Oxford University Press.

Karmiloff-Smith, A. (1994) Mas allá de la Modularidad. Madrid: Alianza

Kuhn, T. (1975). La estructura de las revoluciones cientificas. México: Brevarios, Fondo de cultura económica.

Murcia Peña, N. (2005) Educación y tecnología, un reto hacia el desarrollo humano; la pregunta de la globalización. Revista Plumilla Educativa Nro. 5. Manizales: Universidad de Manizales.

Parra Mosquera Carlos Andrés. (2012). TIC, conocimiento, educación, y competencias tecnológicas en la formación de maestros. Revista Nómadas Nro 36. Bogotá: Universidad Central de Colombia.
Freire, P. (1997). Pedagogía de la Autonomía, saberes necesarios para la práctica educativa. México: Ed. Siglo Veintiuno S.A.

Freire, P. (2003). Grito Manso. México: Ed. Siglo veintiuno, S.A.

Piaget, J. y Inhelder, B. (1955), orig. francés, Castellano (1976) De la lógica del niño a la lógica del adolescente. Ed. Pionera.

Ríos Patiño, A G; Garzón Arcos, M, R, Bonita Paz, M F, Benavides Salazar J. (2013). Revista, Plumilla Educativa, Edición Número 12, Diciembre del 2013. El Miedo en las Prácticas Pedagógicas. Manizales: Universidad de Manizales. Pág. 307-319.

Rodríguez Palmero, M L; Marrero Acosta, J; Moreira Marco, A. (2002). La teoría de los modelos mentales de Johnson-Laird y sus principios: una aplicación con modelos mentales de célula en estudiantes del curso de orientación universitaria, España. Revista Brasileira de Pesquisa em Educação em Ciências, Porto Alegre, v. 2, n. 3, p. 37-57, 2002.

Sabino Carlos (2015), El proceso de investigación científica. Bogotá: Editorial el Cid.

Spelke, E. S. (1991) Physical Knowlwdge in infancy: reflections on Piaget's Theory. En S. Carey y R. Gelman (eds.) Epigenesis of the Mind: Essays in Biology and Knowledge. Erlabaum.

Stegmuller, W. (1991). Filosofia de las ciencias humanas y sociales. Materiales para una fundamentacion cientifica. Barcelona: Anthropos Promat

Vygotsky, L. S. (1977). Pensamiento y Lenguaje. Buenos Aires: Pleyande. 